- This paper considers the ways in which changes in dental education are reflected in the General Dental Council's recent document: The First Five Years - A Framework for Dental Undergraduate Education

- An opinion is given on how this document may be improved to more clearly convey the General Dental Council's view of the product of undergraduate education

\title{
In our opinion: The First Five Years - A framework for Dental Undergraduate Education
}

\author{
J. D. Clark' , L. J. Robertson ${ }^{2}$ and R. M. Harden ${ }^{3}$
}

\begin{abstract}
The second edition of The First Five Years - A framework for Dental Undergraduate Education was published by the General Dental Council (GDC) in August 2002. As with the first edition the overall intention has been to define the scope and content of the undergraduate curriculum. However the second edition includes, for the first time, a list of specific learning outcomes and an appendix with the learning outcomes in a format described by Harden et al., which has been widely adopted in medical education.
\end{abstract}

This addition reflects changes taking place in medical and dental education where the traditional, discipline-based, approach is being replaced by a competency-based approach that requires the reassessment and revision of old curricula. ${ }^{1}$

Since the first edition of the First Five Years there has been an increasing emphasis placed in dentistry, as in other areas, on outcome-based education and on the specification of learning outcomes. Harden et $a .^{2}$ have highlighted the educational benefits of a move to a more outcome-based approach to education, where more emphasis is placed on the product rather than the educational process. There has been significant progress in medicine where there is a move towards international agreement on learning outcomes. ${ }^{3}$ However progress

\footnotetext{
${ }^{1}$ Consultant Orthodontist, Tayside University NHS Trust, Dundee Dental Hospital and School, Park Place, Dundee, DD1 4HN; ${ }^{2 *}$ Curriculum Development Officer, Dundee Dental Hospital and School, Park Place, Dundee, DD1 4HN; ${ }^{3}$ Director of the Centre for Medical Education, University of Dundee, and Director of the Scottish Council for Postgraduate Medical and Dental Education's Education Development Unit, Taypark House, Perth Road, Dundee *Correspondence to: L. Robertson

E-mail:I.j.y.robertson@dundee.ac.uk
}

\section{Refereed Paper}

Received 02.09.02; Accepted 05.12.02

doi:10.1038/sj.bdj.4810394

๑ British Dental Journal 2003; 195: 125-127 has been slower in dentistry where the emphasis is on the detailed specification of competencies. ${ }^{4}$ Whilst there are clear advantages to defining the product of training, there are serious limitations to these historic approaches that emphasise learning objectives rather than learning outcomes.

The GDC have recognised this and are to be congratulated on identifying learning outcomes that define the product of undergraduate education, which they define as 'a caring, knowledgeable, competent and skilful dentist who is able, on graduation, to accept professional responsibility for the effective and safe care of patients, who appreciates the need for Continuing Professional Development, who is able to use advances in relevant knowledge and techniques and who understands the role of the patients in decision making.' ${ }^{5}$

In specifying the learning outcomes they have taken into account the changes that have taken place in dental practice since 1997 and the Quality Assurance Agency for Higher Education benchmarking of academic standards ${ }^{6}$ in dentistry. Topics such as IT skills; Law, ethics, professionalism; Integration with the education of Professionals Complementary to Dentistry; Health and safety issues; Outreach teaching; and the need for continuing pro- fessional development and Pain and anxiety control are emphasised.

The report encourages a longitudinal approach to these subjects, incorporating them in the curriculum rather than regarding them as 'bolt on' extras. There is also a suggestion that there should be further integration with Biomedical Sciences and subjects comprising Human Diseases.

\section{LEARNING OUTCOMES IN THE FIRST FIVE YEARS}

Learning objectives are to be found in Parts 1 and 2 of the document and in an appendix. They are presented in a different format in each part and in the appendix.

In Part 1 generic learning outcomes are listed under three area headings: Knowledge and Understanding; Skills; Attitudes.

In Part 2, learning outcomes are presented in syllabus format as 'subjects and topics' and also listed as 'specific learning outcomes' at the end of this section. They are expressed at three defined levels:

\section{- Be competent at:}

Students should have a sound theoretical knowledge and understanding of the subject together with an adequate clinical experience to be able to resolve clinical problems encountered, independently, or without assistance. 
- Have knowledge of:

Students should have a sound theoretical knowledge of the subject, but need have only a limited clinical/practical experience; - Be familiar with:

Students should have a basic understanding of the subject, but need not have direct clinical experience or be expected to carry out procedures independently;

In the appendix learning outcomes are presented using the three-circle format described by Harden et al. ${ }^{7}$ for specifying learning outcomes in medical education.

\section{IN OUR OPINION}

In our opinion the specification of learning outcomes in the second edition is a significant advance over the previous edition and the three-circle outcome model used in the appendix of the report presents clearly the Council's view of the curriculum. However, as more experience is gained with an outcome-based approach to education in dentistry, the GDC may wish to consider providing, for the learning outcomes, a more consistent framework throughout their report and to modify the framework in the appendix to meet the specific needs in dentistry.

It may be confusing to find in the report several different approaches to the specification of learning outcomes. First the report lists generic learning outcomes in three broad areas: Knowledge and Understanding; Skills; Attitudes. It has been argued that this traditional approach is not appropriate for the spectrum of competences required of healthcare professionals ${ }^{8}$ and this presentation of outcomes does not emphasise the need to integrate knowledge and skills into comprehensive patient care.

Second, curriculum subjects and topics have been presented in a syllabus format and third, learning outcomes have been presented as a list and as an appendix in the format described by Harden et al. ${ }^{7}$ for specifying learning outcomes in medicine - the 'three-circle model'. Harden et al. ${ }^{2}$ suggest that learning objectives should be clear and unambiguous and provide a clear overview of the undergraduate curriculum. In our opinion, in its present form, the second edition does not achieve this as the learning objectives are to be found in three separate sections of the document, each in a different format. Future revisions of the report could be improved by using the three-circle approach presented in the appendix as the framework for the whole report.

Consideration should also be given to adapting the framework to meet the specific needs in dentistry. A modified three-circle model has already been described for dentistry $^{9}$ and is an ideal model to encapsulate the learning outcomes identified in the First Five Years and draw together the learning objectives in the three separate sections of the document presenting them in a unified format (Fig. 1).

The model is similar to the medical model for classifying learning outcomes and is based on the three dimensions of the work of a dentist as a competent and reflective practitioner. These are:

- What the dentist is able to do ('doing the right thing' - ie technical intelligencies).
- How the dentist approaches their practice ('doing the thing right' - intellectual, emotional, analytical and creative intelligencies).

- The dentist as a professional ('the right person doing it' - ie personal intelligencies).

Dentistry however is a highly technical profession with the majority of patient encounters involving some form of interventive treatment, either operative or therapeutic. In the dental modification therefore the learning outcomes are grouped to naturally follow the pattern of a patient encounter in the dental setting.

The inner circle, What the dentist is able to do' includes three key tasks: Clinical information gathering, Treatment planning and Treatment procedures. These tasks represent the practical aspects of patient care. The dentist, however, brings much more than practical skills to the patient encounter.

'How the dentist approaches their practice' or what they bring to the treatment of each patient, as specified in the middle circle includes: Application of basic clinical sciences; Clinical reasoning and judgement; Communication; Health promotion; Attitudes, ethical stance and legal responsibilities and Information handling.

The final dimension to the three-circle outcomes model is 'The dentist as a professional'. This encompasses: the Role of the dentist within the Health Service and Personal development. These domains can be further sub-divided into more detailed learning outcomes. ${ }^{9}$

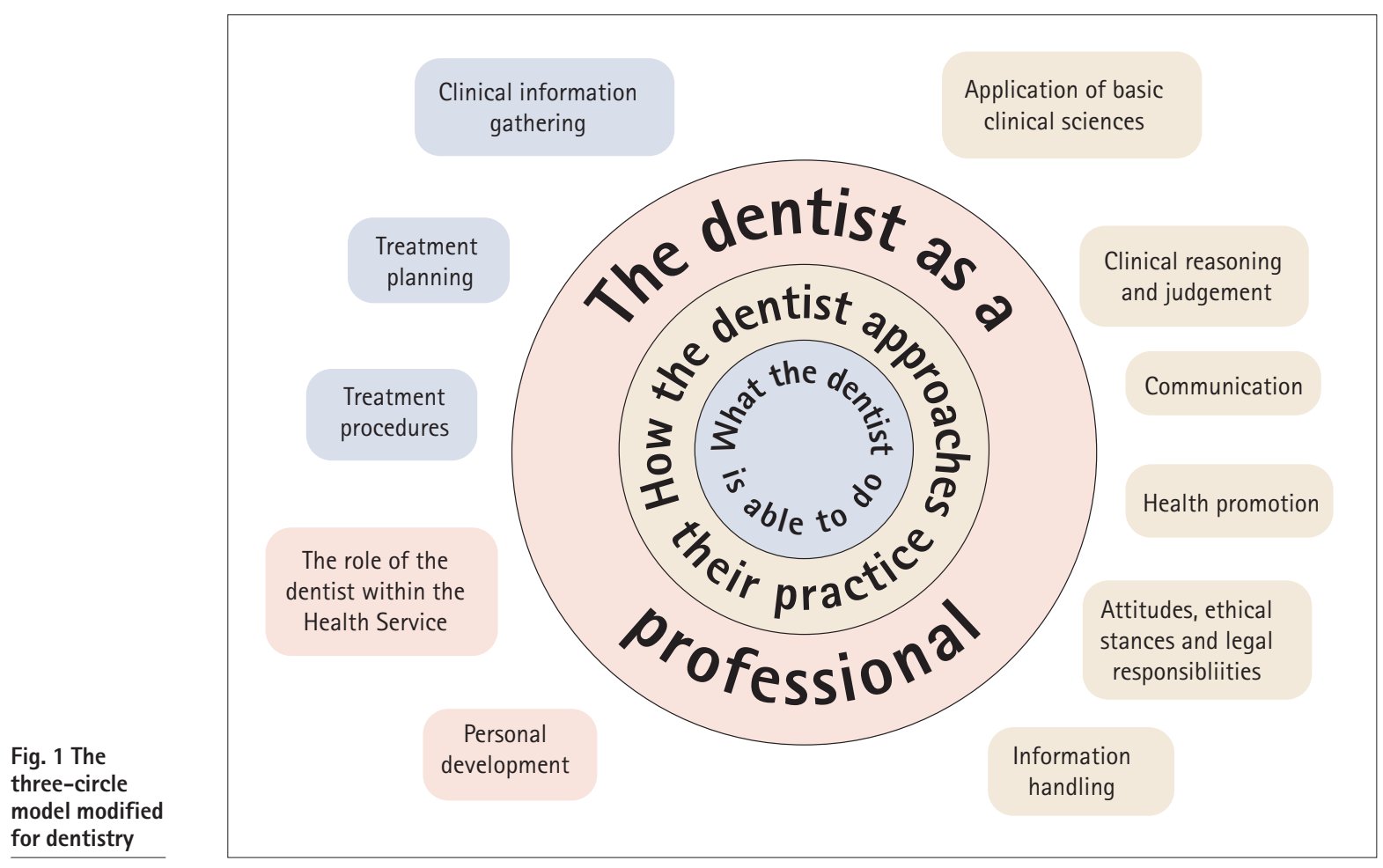




\section{CONCLUSIONS}

The three-circle outcome-based approach to education suitably modified for dentistry provides a useful tool to support the GDC's desire 'to encourage the further development of progressive ideas and improved methods of study in what should be a dynamic educational process'.

It emphasises personal development of students as a desirable learning outcome and also that "the primary dental degree or diploma represents only the first stage in an educational continuum which should last throughout a dentist's practising life'.

The GDC report draws attention to the fact that "the curriculum must prepare students to undertake self-directed learning throughout their professional lives.' The three-circle model can be used to convey the curriculum through the different phases of dental education.

The GDC emphasises that assessments and examinations should be designed with the aim and generic and specific learning outcomes in mind.

A grid in which the eleven key outcomes in the three-circle model are charted against the different assessment tools that can be used will help to ensure that there is a close match between learning outcomes, teaching methods and assessment.

1. Yip H K, Smales R J. Review of competency-based education in dentistry. Br Dent J 2000; 189: 324-326.

2. Harden R M. Developments in outcome-based education. Med Teacher 2002; 24: 117-120.

3. Institute for International Medical Education. Global
Minimum Essential Requirements in Medical Education. Med Teacher 2002; 24: 130 -135.

4. Prescott LE, McKinlay P, Rennie J S. The Development of an Assessment System for Dental Vocational Training and General Professional Training; a Scottish Approach. Br Dent J 2002; 190: 41-44.

5. General Dental Council. The First Five Years A Framework for Undergraduate Dental Education. 2nd edn. London, The General Dental Council, 2002

6. Quality Assurance Agency for Higher Education. Subject Benchmark Statements. Academic Standards - Dentistry. Gloucester: Quality Assurance Agency for Higher Education, 2002.

7. Harden R M, Crosby J R, Davis M H, Friedman M. AMEE Guide No 14: Outcome Based Education; Part 5 - from Competency to Meta-competency: A Model for the Specification of Learning Outcomes. Association for Medical Education in Europe, 1999.

8. Harden R M. Learning Outcomes and Instructional Objectives - Is there a difference? Med Teacher 2002; 24: 151-155.

9. Clark J D, Robertson LJ, Harden R M. The specification of learning outcomes in Dentistry. Br Dent J (in press) 